\title{
Early Intracranial Aneurysm Recurrence after Microsurgical Clip Ligation: Case Report and Review of the Literature
}

\author{
Serge Marbacher ${ }^{1} \quad$ Alexander Spiessberger $^{1} \quad$ Michael Diepers $^{2} \quad$ Luca Remonda ${ }^{2}$ Javier Fandino ${ }^{1}$ \\ ${ }^{1}$ Department of Neurosurgery, Kantonsspital Aarau (KSA), \\ Aarau, Switzerland \\ 2 Division of Neuroradiology, Department of Radiology, Kantonsspital \\ Address for correspondence Serge Marbacher, MD, PhD, Department \\ of Neurosurgery, Kantonsspital Aarau (KSA), Tellstrasse 1, Aarau \\ Aarau (KSA), Aarau, Switzerland \\ 5000, Switzerland (e-mail: serge.marbacher@ksa.ch).
}

J Neurol Surg Rep 2018;79:e93-e97.

\begin{abstract}
Keywords

- intracranial aneurysm

- clipping

- aneurysm recurrence

- subarachnoid hemorrhage

Microsurgical clip ligation is considered a definitive treatment for intracranial aneurysms (IAs), resulting in low rates of local recurrence that range from 0.2 to $0.5 \%$ and a latency period that averages about a decade. Our case report describes an early asymptomatic recurrence (i.e., without sentinel headache or seizure) less than 1 year after this 20-year-old woman underwent clip ligation of a ruptured anterior communicating artery (AComA) aneurysm. At recurrence, the patient underwent coiling of the regrowth; follow-up imaging at 6 and 18 months demonstrated complete IA occlusion. To review the putative risk factors of this rare phenomenon, the authors searched the PubMed database using the keywords "intracranial aneurysm," "recurrence," and "clipping" in various combinations. In the seven cases identified, all occurred in initially ruptured IA, which was often at the AComA, and six of seven patients were younger than 50 years old. Although most IA remnants grow slowly, early recurrence may represent a more aggressive biological behavior that warrants special attention in younger patients, positive rupture status, and unintended remnant of any size. In such a constellation, early imaging follow-up within the first 6 months may be warranted to rule out early IA recurrence
\end{abstract}

\section{Introduction}

The annual risk of recurrence is very low, ranging from 0.02 to $0.52 \%^{1-3}$ for a completely clipped intracranial aneurysm (IA), but substantially higher, ranging from 0.38 to $7.3 \%$ in a known residual. ${ }^{1-4}$ There is growing consensus based on these figures that long-term surveillance in patients with residual IAs after clip ligation is needed. However, no protocol is yet established that defines timing or optimal modality of follow-up imaging. Time to IA recurrence after clipping averages nearly a decade $\mathrm{e}^{5-7}$ and rate of regrowth is likely slow, ${ }^{8}$ less than $0.5 \mathrm{~mm}$ per year in regrowing residuals in a recent cohort. ${ }^{2}$ Significant causes for increased unexpected findings (including IA remnants) in postsurgical digital subtraction angiography (DSA) can include location, complex morphology, and large aneurysm size..$^{9-11}$

Robust risk factors for IA recurrence and growth of IA remnants after clip ligation are not established. Our case report describes an early asymptomatic recurrence of less than 1 year in a 20-year-old woman who underwent clip ligation of a ruptured anterior communicating artery (AComA) aneurysm. We then review the literature to summarize findings in similar cases of early recurrence and hypothesize potential predictors that warrant early imaging follow-up. received

March 23, 2018 accepted after revision

September 20, 2018
DOI https://doi.org/

10.1055/s-0038-1676454. ISSN 2193-6358. (c) 2018 Georg Thieme Verlag KG
Stuttgart · New York

License terms

c) $(1) Ð$ 


\section{Case Report and Review of the Literature}

\section{Search Strategy}

The literature search has been performed in accordance with PRISMA guidelines guidelines. ${ }^{12}$ Per June 15th, 2016, the PubMed database was searched to identify all case reports and case series of patient with local IA recurrence after microsurgical neck clipping. This search strategy was used as a subproject of a large systematic meta-analysis on de novo IA formation and recurrence after neck clipping. ${ }^{13}$

\section{Clinical Presentation}

A 20-year-old woman patient presented with syncope and impaired consciousness with a Glasgow Coma Scale 12, severe headache, meningismus, recurrent vomiting, and hypertensive crisis but had no focal neurological deficits. Medical history revealed no report of sentinel headache, no evidence of epileptic seizure, and no IA risk factors (i.e., negative family history, nonsmoker, no hypertension, absent drug abuse). The patient was otherwise healthy and was not taking any medications. There were no signs for polycystic kidney disease or Marfan syndrome. Magnetic resonance imaging findings demonstrated extensive subarachnoid hemorrhage (SAH) (Fisher grade 4) with an acute left-sided 2-mm subdural hematoma. Magnetic resonance angiography revealed a small irregularly shaped IA of the AComA complex as putative source of SAH. With this diagnosis, the patient was referred to our institution.

\section{Admission Workup}

At admission, the patient was immediately taken to the hybrid operating room (hOR). Four-vessel cerebral DSA including standard views, additional IA specific views, and a volumetric sequence to reconstruct three-dimensional (3D) angiographic and multiplanar computed tomography (CT) images confirmed a small $(3 \times 3.5 \mathrm{~mm})$ relatively broad-based AComA aneurysm predominantly supplied from the left anterior cerebral artery. 3D-DSA did not detect any additional IA. The aneurysm itself had an irregularly shaped surface that included multiple blebs and a small secondary aneurysm protruding from the fundus (daughter aneurysm). The admission workup is summarized in - Fig. 1.

\section{Treatment}

With consensus between the attending interventional neuroradiologist and neurosurgeon, the patient underwent a left pterional craniotomy and IA clipping in the hOR. During visual inspection after pilot clip ligation, the aneurysm ruptured close to the base. The initial clip was repositioned and a second clip was placed. Repeat visual inspection, Doppler sonography, and indocyanine green video angiography demonstrated complete IA occlusion and patent A2 segments. Intraoperative 3D-DSA confirmed complete obliteration of the irregularly shaped regions of the aneurysm and revealed a small $(1 \times 1.5 \times 1 \mathrm{~mm})$ posteriorly projecting IA remnant that was surgically unsuitable for clip replacement or wrapping (-Fig. 2). Postoperatively, the patient initially demonstrated clinical improvement with increased consciousness and normal findings on day 1 postoperative CTscan. During the next 3 days, she became hydrocephalic and underwent external ventricular drainage, and developed medically refractory delayed cerebral vasospasm. On days 6, 8, and 12 after IA rupture, endovascular treatment was used as a rescue therapy with intra-arterial nimodipine infusion. During this period, the patient developed prolonged nonconvulsive status epilepticus, progressive brain swelling, and intractable intracranial pressure that necessitated decompressive hemicraniectomy. The patients condition stabilized, and she was discharged on day 44 to a rehabilitation facility (modified Rankin Scale 4).

\section{Follow-Up}

Two months after rehabilitation and complication-free period after reimplantation of the autologous bone flap, the patient showed good recovery (modified Rankin Scale 2) but
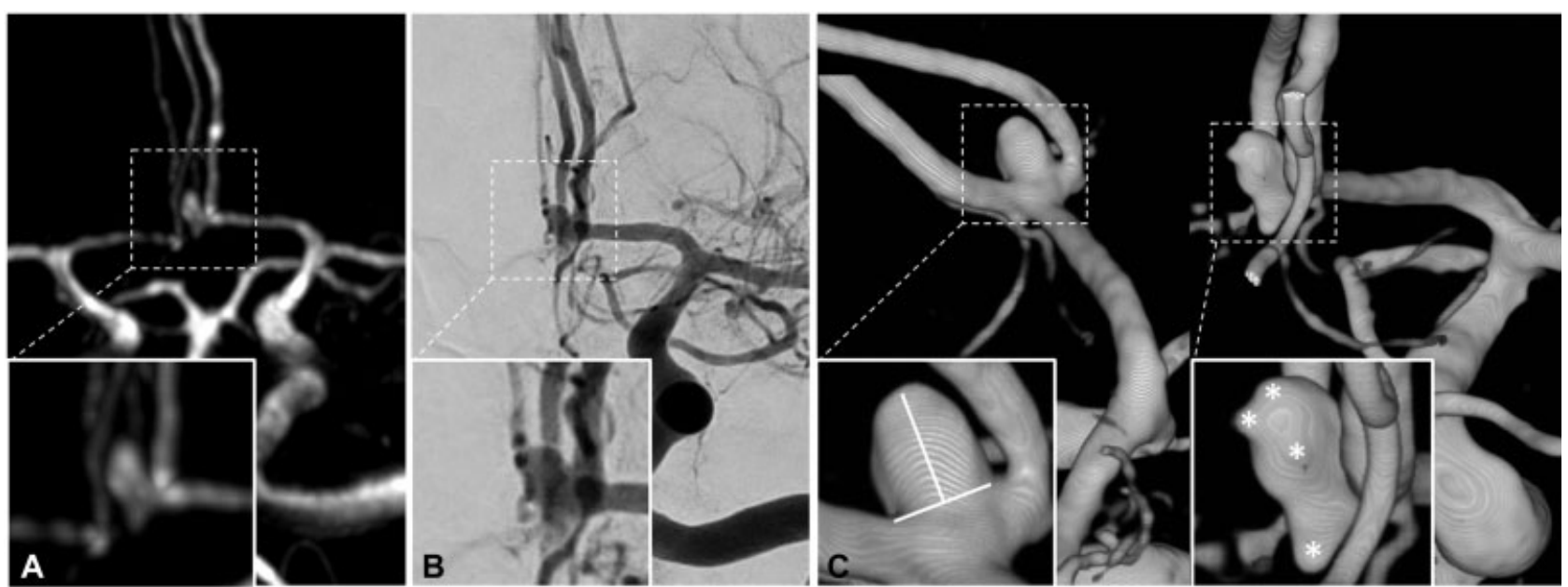

Fig. 1 Admission workup for 20-year-old patient. Initial magnetic resonance angiogram revealed a small ruptured left-sided anterior communicating artery aneurysm (A). Subsequent four-vessel two-dimensional digital subtraction angiography (2D-DSA) confirmed the single aneurysm predominantly supplied from the right anterior cerebral artery (B). 3D-DSA clarified the angioarchitecture and visualized a small $(3 \times 3.5$ mm) relatively broad-based aneurysm (C, left inset). Virtual rotation revealed an irregular shaped surface with posteriorly projecting multiple blebs and tiny daughter aneurysms protruding from the aneurysm fundus $\left(\boldsymbol{C}\right.$, right inset, $\left.{ }^{*}\right)$. 


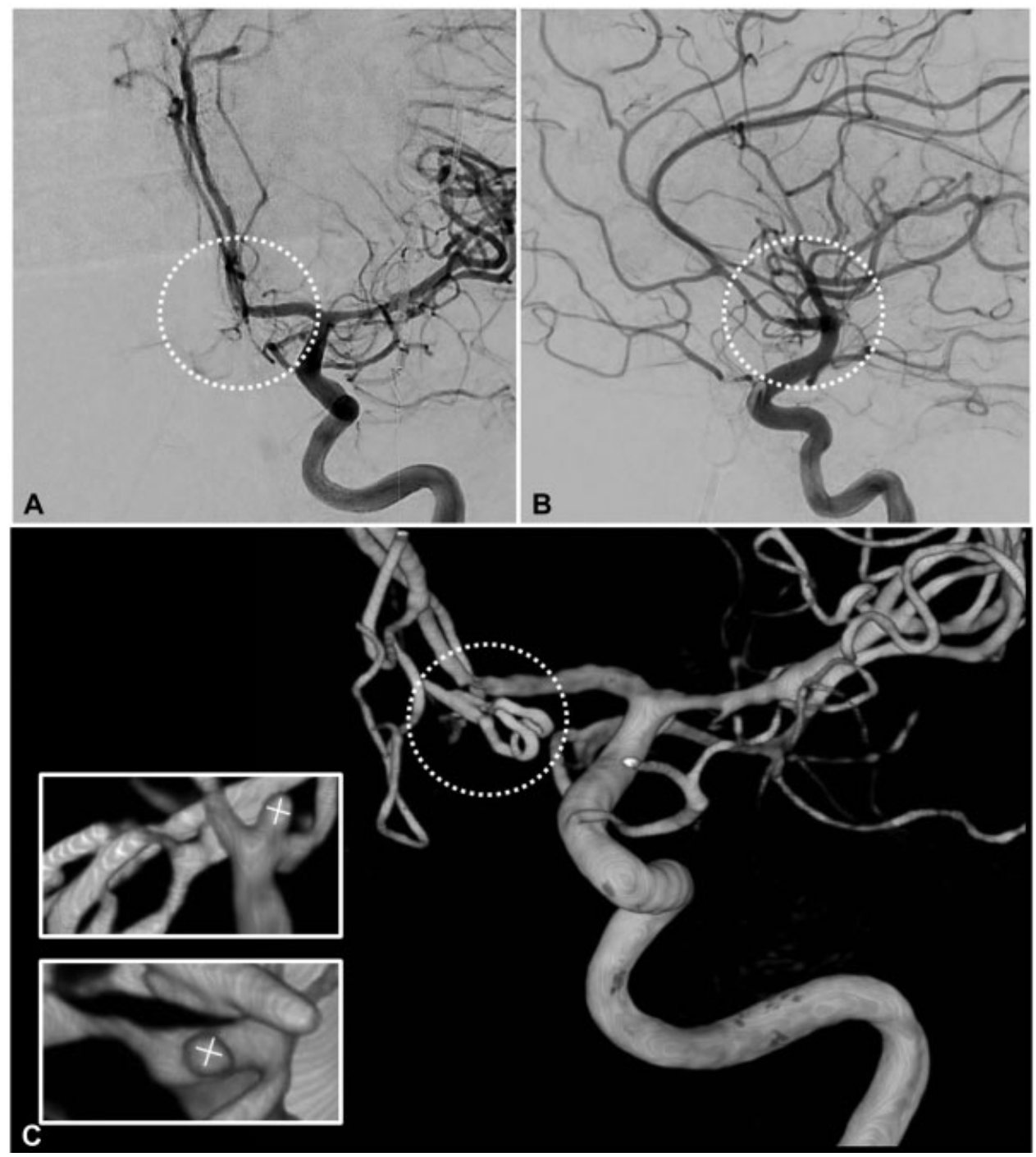

Fig. 2 Intraoperative remnant. Standard intraoperative two-dimensional digital subtraction angiography (2D-DSA) in anteroposterior (A) and lateral (B) projections shows the small remnant is barely visible and obscured by surrounding vessels. In multiplanar intraoperative 3D-DSA (C), viewing angles are unrestricted. Clipped intracranial aneurysm complex can be virtually rotated in any direction (C, inset) to identify and measure the small dog-ear remnant $(1 \times 1.5 \times 1 \mathrm{~mm})$ without interference of clip masses or adjacent vessels.

declined the planned 6-month follow-up imaging. At annual follow-up examination, angiography demonstrated a large $(7 \times 11 \mathrm{~mm})$ recurrence. With consensus of our interdisciplinary team, the patient underwent coiling of the regrown IA. At 6- and 18-month follow-up, DSA studies demonstrated complete IA occlusion ( - Fig. $\mathbf{3}$ ).

\section{Discussion}

Despite the general late recurrence and slow growth rate of IA remnants after microsurgical clip ligation, our case report demonstrates a rare instance of an early and rapid IA recurrence from a tiny 1-mm aneurysm remnant. Although risk factors for remnants after clipping are known, how these factors cause recurrence and growth of such IA remnants is not established.

\section{Location as Risk Factor for IA Remnant}

Intracranial location has been recognized as a predictor of incomplete aneurysm occlusion after clipping. ${ }^{9-11,14,15}$
Compared with the middle cerebral artery (MCA), higher rates of incomplete occlusion after clip obliteration were associated with aneurysms located at the AComA complex or posterior circulation. Recently, a multivariate analysis confirmed IA location (ACA $>$ ICA $>$ PC $>$ MCA) as a significant risk factor for leaving an IA remnant post-clipping. Along with our patient's aneurysm located at the AComA, our literature review identified early postoperative recurrences located at the AComA complex in four cases, basilar artery in two cases, and posterior communicating artery in one case. A growing body of evidence suggests that aneurysms of the AComA harbor an increased risk of rupture. ${ }^{16,17}$ One hypothesis is that underlying biological factors not only influence risk of rupture of an AComA aneurysm but also increase risk of recurrence and growth after clipping. ${ }^{18}$

\section{Age as Risk Factor for Remnant Growth}

In a 2016 multivariate analysis, Jabbarli et al determined that age was an independent risk factor for remnant growth. ${ }^{19} \mathrm{In}$ 

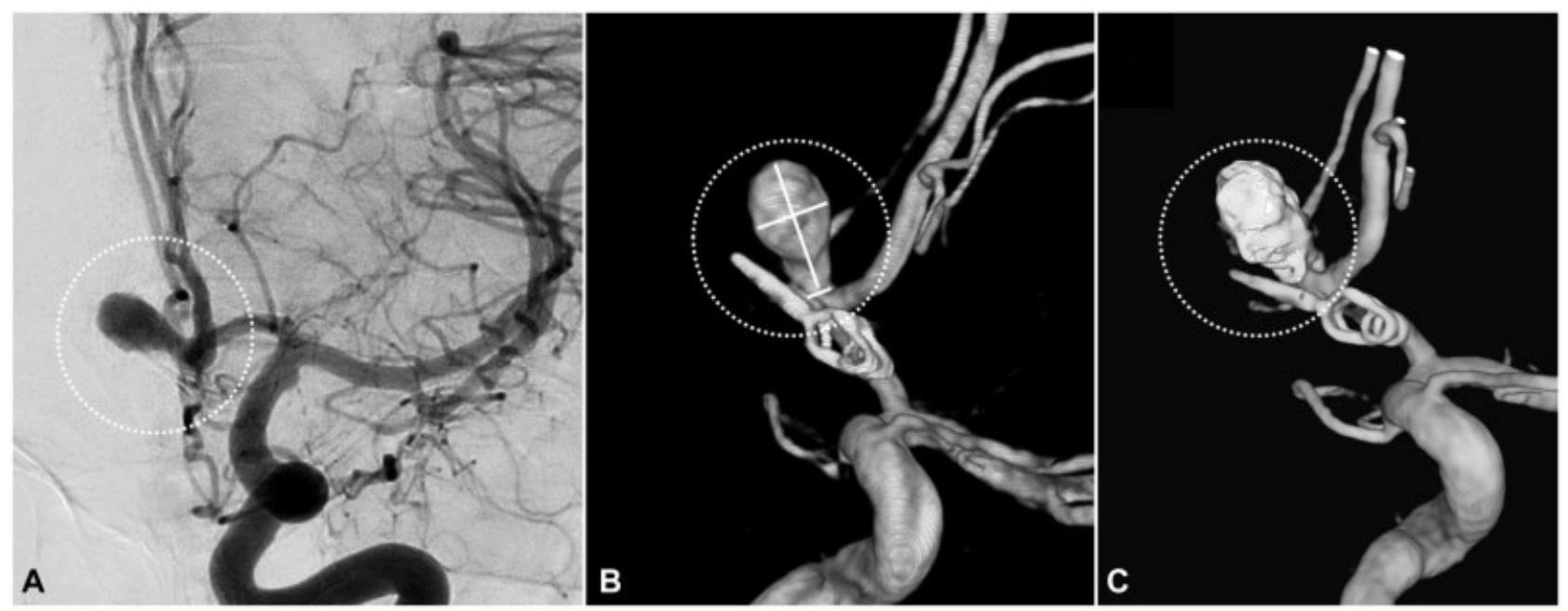

Fig. 3 Recurrence, retreatment, and follow-up. Follow-up of two-dimensional digital subtraction angiography (2D-DSA) and 3D-DSA 12 months after clipping depicting a large recurrence $(7 \times 10 \mathrm{~mm})$ with small neck $(3 \mathrm{~mm})$ exactly at the site of the intraoperatively documented aneurysm remnant (A and B). After coiling, this aneurysm showed stable, complete occlusion at 6 and 18 months (C) after retreatment.

review of variables of patient characteristics, the authors identified that those less than 45 years of age were at risk of higher rates of remnant growth (odds ratio $>33$ ). In a large population-based cohort, Lindgren et al found younger age at first IA diagnosis was significantly associated with de novo IA formation. ${ }^{20}$ In our literature review, five of seven cases with early IA recurrence were younger than 50 years of age (-Table 1 ) and our patient was exceptionally young at 20 years of age.

\section{Size as Risk Factor for Remnant Regrowth}

Although some authors found increased risk of IA recurrence with increasing size of residual aneurysm, ${ }^{19,24,25}$ others found no association between remnant size and risk of regrowth. ${ }^{2,4}$ Our patient's residual aneurysm was very small $(1 \times 1 \mathrm{~mm})$. In the seven cases of early recurrence in our review, three cases did not specify whether a remnant was present, and four cases deemed complete occlusion of the IA.
However, small remnants could have been missed. Compared with the much higher detection rate of small-sized IA remnants ${ }^{26,27}$ with 3D-DSA, 2D intra- or postoperative DSA or CT angiography is more limited in ruling out such small remnants. Like our patient, higher detection rates of small residuals are now more likely because of intra- or postoperative $3 D-D S A .^{28}$

\section{Other Potential Risk Factors for IA Remnant Growth}

In the most recent series from a prospective database with long-term follow-up by means of DSA, no association was found between postoperative residual growth and multiple IAs, fusiform morphology, clip reconstruction, or SAH. ${ }^{2}$ In a 2013 series of 26 patients with IA recurrences, Spiotta et al noted 21 patients with a positive rupture status. ${ }^{6}$ They hypothesized that the biological difference between ruptured and unruptured IAs was the determining factor for IA recurrence after clipping. All reporting early $(<1$ year) IA

Table 1 Patient characteristics of IA recurrences within 1 year after clip ligation

\begin{tabular}{|l|l|l|l|l|l|l|}
\hline Author/year & $\begin{array}{l}\text { Interval } \\
\text { (months) }\end{array}$ & $\begin{array}{l}\text { Age } \\
\text { (years) }\end{array}$ & Sex & $\begin{array}{l}\text { Rupture } \\
\text { status }\end{array}$ & Location & IA occlusion grade/imaging modality \\
\hline $\begin{array}{l}\text { Adamson and Batjer } \\
(1988)^{21}\end{array}$ & 2 & 50 & $\mathrm{~m}$ & SAH & BA & Complete occlusion/intraoperative 2D-DSA \\
\hline Asgari et al $(2003)^{22}$ & 1 & 66 & $\mathrm{~F}$ & SAH & AComA & Complete occlusion/postoperative 2D-DSA \\
\hline Cekirge et al $(2000)^{23} 2000$ & 2 & 40 & $\mathrm{~m}$ & SAH & AComA / & Not reported \\
\hline el-Beltagy et al $(2010)^{5}$ & 12 & 40 & $\mathrm{~F}$ & SAH & PCA & Complete occlusion/postoperative 2D-DSA \\
\hline & 12 & 49 & $\mathrm{~F}$ & SAH & BA & Complete occlusion/postoperative 2D-DSA \\
\hline Spiotta et al $(2013)^{6}$ & 1 & 48 & $\mathrm{~F}$ & SAH & AComA & Not reported \\
\hline & 4 & 62 & $\mathrm{~m}$ & SAH & AComA & Not reported \\
\hline Present case report & 12 & 20 & $\mathrm{~F}$ & SAH & AComA & Dog-ear remnant/3D-iDSA, ICGA \\
\hline
\end{tabular}

Abbreviations: 2D-DSA, two-dimensional digital subtraction angiography; 3D-iDSA, Three-dimensional intraoperative digital subtraction angiography; AComA, anterior communicating artery; BA, basilar artery; IA, intracranial aneurysm; ICGA, indocyanine green angiography; PComA, posterior communicating artery; $\mathrm{SAH}$, subarachnoid hemorrhage. 
recurrences (including our case) to date were found in patients with a previous history of SAH from the clipped IA.

Discussion regarding risk factors for IA remnant growth is complicated by what defines postoperative IA residual and recurrence. For example, Burkhardt et al grouped postoperative residuals into intentional and unintentional remnants. ${ }^{2}$ Their data suggest a benign nature of intentional residuals that are left to preserve branch arteries. From a biological point of view, residuals left intentionally to preserve perforators or branching arteries presumably consist of healthy vessel walls, whereas unintended remnants represent diseased IA walls that are more likely to undergo further degeneration and eventually growth. In our patient, the unintended remnant represented a tiny bleb of the IA wall and was not part of a parent artery or small perforator. An earlier hypothesis proposed that pathobiological differences of IA remnants contribute to the delay (time course) between surgery and recurrence: that is, an early, more rapid recurrence resulted from a persistent wall weakness (unintentionally left IA residual) and late, slower recurrence from de novo vessel wall degeneration. ${ }^{6}$

In summary, some evidence exists that young age and positive rupture status predisposes a patient for IA remnant growth. It remains controversial and partially unknown whether IA (size, morphology, clip reconstruction technique, flow dynamics) and patient-specific factors (multiple IA, previous SAH, family history, smoking, hypertension) known to influence growth of unruptured IA likewise influence growth of IA remnants. Although most IA remnants after clipping grow slowly, early recurrence may represent a more aggressive biological behavior that warrants special attention in younger patients, positive rupture status, and unintended remnant of any size. In such a constellation, early imaging follow-up within the first 6 months may be warranted to rule out early IA recurrence.

\section{References}

1 Brown MA, Parish J, Guandique CF, et al. A long-term study of durability and risk factors for aneurysm recurrence after microsurgical clip ligation. J Neurosurg 2017;126(03):819-824

2 Burkhardt JK, Chua MHJ, Weiss M, Do ASS, Winkler EA, Lawton MT. Risk of aneurysm residual regrowth, recurrence, and de novo aneurysm formation after microsurgical clip occlusion based on follow-up with catheter angiography. World Neurosurg 2017;106:74-84

3 David CA, Vishteh AG, Spetzler RF, Lemole M, Lawton MT, Partovi S. Late angiographic follow-up review of surgically treated aneurysms. J Neurosurg 1999;91(03):396-401

4 Feuerberg I, Lindquist C, Lindqvist M, Steiner L. Natural history of postoperative aneurysm rests. J Neurosurg 1987;66(01):30-34

5 el-Beltagy M, Muroi C, Roth P, Fandino J, Imhof HG, Yonekawa Y. Recurrent intracranial aneurysms after successful neck clipping. World Neurosurg 2010;74(4-5):472-477

6 Spiotta AM, Hui F, Schuette A, Moskowitz SI. Patterns of aneurysm recurrence after microsurgical clip obliteration. Neurosurgery 2013;72(01):65-69, discussion 69

7 Tsutsumi K, Ueki K, Morita A, Usui M, Kirino T. Risk of aneurysm recurrence in patients with clipped cerebral aneurysms: results of long-term follow-up angiography. Stroke 2001;32(05):1191-1194

8 Ihm EH, Hong CK, Shim YS, Jung JY, Joo JY, Park SW. Characteristics and management of residual or slowly recurred intracranial aneurysms. J Korean Neurosurg Soc 2010;48(04):330-334
9 Alexander TD, Macdonald RL, Weir B, Kowalczuk A. Intraoperative angiography in cerebral aneurysm surgery: a prospective study of 100 craniotomies. Neurosurgery 1996;39(01):10-17, discussion 17-18

10 Origitano TC, Schwartz K, Anderson D, Azar-Kia B, Reichman OH. Optimal clip application and intraoperative angiography for intracranial aneurysms. Surg Neurol 1999;51(02):117-124, discussion 124-128

11 Payner TD, Horner TG, Leipzig TJ, Scott JA, Gilmor RL, DeNardo AJ. Role of intraoperative angiography in the surgical treatment of cerebral aneurysms. J Neurosurg 1998;88(03):441-448

12 Moher D, Shamseer L, Clarke M, et al; PRISMA-P Group. Preferred reporting items for systematic review and meta-analysis protocols (PRISMA-P) 2015 statement. Syst Rev 2015;4:1

13 Spiessberger A, Vogt D, Fandino J, Marbacher S. Formation of intracranial de novo aneurysms and recurrence after neck clipping - a systematic review and meta-analysis. AANS Annual Scientific Meeting 2018 April 28-May 2, New Orleans, 2018

14 Kivisaari RP, Porras M, Ohman J, Siironen J, Ishii K, Hernesniemi J. Routine cerebral angiography after surgery for saccular aneurysms: is it worth it? Neurosurgery 2004;55(05):1015-1024

15 Nakase H, Kamada Y, Aoki H, Goda K, Morimoto T, Sakaki T. Clinical study on recurrent intracranial aneurysms. Cerebrovasc Dis 2000;10(04):255-260

16 Bijlenga P, Ebeling C, Jaegersberg M, et al; @neurIST Investigators. Risk of rupture of small anterior communicating artery aneurysms is similar to posterior circulation aneurysms. Stroke 2013; 44(11):3018-3026

17 Morita A, Kirino T, Hashi K, et al; UCAS Japan Investigators. The natural course of unruptured cerebral aneurysms in a Japanese cohort. N Engl J Med 2012;366(26):2474-2482

18 Marbacher S, Niemelä M, Hernesniemi J, Frösén J. Recurrence of endovascularly and microsurgically treated intracranial aneurysms-review of the putative role of aneurysm wall biology. Neurosurg Rev 2017

19 Jabbarli R, Pierscianek D, Wrede K, et al. Aneurysm remnant after clipping: the risks and consequences. J Neurosurg 2016;125(05): 1249-1255

20 Lindgren AE, Räisänen S, Björkman J, et al. De novo aneurysm formation in carriers of saccular intracranial aneurysm disease in eastern Finland. Stroke 2016;47(05):1213-1218

21 Adamson T, Batjer H. Aneurysm recurrence associated with induced hypertension and hypervolemia. Surg Neurol 1988;29 (01):57-61

22 Asgari S, Wanke I, Schoch B, Stolke D. Recurrent hemorrhage after initially complete occlusion of intracranial aneurysms. Neurosurg Rev 2003;26(04):269-274

23 Cekirge HS, Islak C, Firat MM, Kocer N, Saatci I. Endovascular coil embolization of residual or recurrent aneurysms after surgical clipping. Acta Radiol 2000;41(02):111-115

24 Drake CG, Vanderlinden RG. The late consequences of incomplete surgical treatment of cerebral aneurysms. J Neurosurg 1967;27 (03):226-238

25 Yang K, Park JC, Ahn JS, Kwon DH, Kwun BD, Kim CJ. Characteristics and outcomes of varied treatment modalities for partially thrombosed intracranial aneurysms: a review of 35 cases. Acta Neurochir (Wien) 2014;156(09):1669-1675

26 Ahn SS, Kim YD. Three-dimensional digital subtraction angiographic evaluation of aneurysm remnants after clip placement. J Korean Neurosurg Soc 2010;47(03):185-190

27 Kang HS, Han MH, Kwon BJ, et al. Postoperative 3D angiography in intracranial aneurysms. AJNR Am J Neuroradiol 2004;25(09): 1463-1469

28 Dammann P, Jägersberg M, Kulcsar Z, Radovanovic I, Schaller K, Bijlenga P. Clipping of ruptured intracranial aneurysms in a hybrid room environment-a case-control study. Acta Neurochir (Wien) 2017;159(07):1291-1298 